\title{
Electrodeposition of Zn-Co Alloy from an Acid Sulphate Bath Containing Triethanolamine and Thiaminehydrochloride
}

\author{
V. Narasimhamurthy ${ }^{1, *}$, L.H. Shivashankarappa ${ }^{2}$ \\ ${ }^{1}$ Government First Grade College and Post Graduate Study Center, Shivamogga - 577 201, Karnataka, India. \\ ${ }^{2}$ Maharani Science College for Women, Palace Road, Bengaluru - 560 001, Karnataka, India.
}

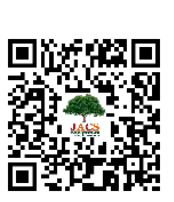

\section{A R T I C LE DE T A I L S}

Article history:

Received 07 December 2020

Accepted 27 December 2020

Available online 17 January 2021

\section{Keywords:}

Electrodeposition

Zinc-Cobalt Alloy

Triethanolamine (TEA)

Cathodic Current Efficiency

\begin{abstract}
A B S T R A C T
Electrodeposition of Zn-Co alloy from an acid sulphate bath has been carried out in this research work. The effects of metal ion ratio in the bath, $\mathrm{pH}$ current density, temperature, stirring, thickness and concentrations of triethanolamine and thiaminehydrochloride on the alloy composition and on cathodic current efficiency have been investigated. The deposition potentials of Zn-Co alloy are less noble of zinc and cobalt. The structure of Zn-Co alloy was investigated by X-ray diffraction indicates zinc structure. The surface morphology of alloy deposits is found to depend on the percentage of cobalt in the alloy. Under the optimum operating conditions, Zn-Co alloy deposition follows anomalous co-deposition.
\end{abstract}

\section{Introduction}

In the recent years, many efforts have been made to develop high corrosion resistant steel for automotive and body building works [1, 2]. Extensive work has been reported [3-5] in the area of development of zinc alloys to provide high degree of corrosion resistance. Among several zinc alloys electroplated, zinc alloyed with low percentage of cobalt $(<1 \%)$ is the most commercially viable option for cost effectiveness and for better corrosion resistance than conventional zinc system. Zn-Co alloys have been electrodeposited from acid chloride [6-8] and sulphate $[9,10]$ baths. Current density, temperature and $\mathrm{pH}$ were found to increase the percentage of cobalt in the alloy. Zn-Co alloy deposition was found to follow anomalous type of co-deposition [11,12]. The presence of some of the additives like germanium, arsenic and antimony reduces the anomalous behavior to a small extent $[13,14]$. Literature survey on $\mathrm{Zn}-\mathrm{Co}$ alloy plated from acid sulphate baths indicates that baths exhibit poor throwing power and low cathodic current efficiencies. An attempt has been made in this study to formulate a suitable bath and to determine an optimum operating condition required for the deposition of $\mathrm{Zn}$-Co alloy containing $0.4-1.2 \%$ Co having high cathodic current efficiency.

\section{Experimental Methods}

Plating bath solutions were prepared from laboratory grade chemicals using distilled water. The bath solution was filtered and purified as described by elsewhere. Copper foil $\left(1 \mathrm{~cm}^{2}\right.$, and $0.4 \mathrm{~mm}$ thick) was used as a cathode and a stainless-steel anode $\left(2 \mathrm{~cm}^{2}\right)$ was used as an auxiliary electrode. Electrodeposition was carried out galvanostatically. To determine the composition of alloy, alloy deposits were dissolved in $20 \%$ $\mathrm{HNO}_{3}$ and analyzed for metal content by atomic absorption spectrometry (Varian spectra model AA 30). Deposition potentials were measured w.r.t. SCE with the help of a scanning potentiostat [Elico (India) CL 35]. The adhesion of alloy to base metal was tested by a standard bending test. Porosity of alloy deposits was determined by Ferroxyl test. Phase structure of $\mathrm{Zn}$-Co alloy deposits was determined by X-ray powder diffraction (filter $\mathrm{Cuk}_{1}, 30 \mathrm{KV}, 20 \mathrm{~mA}, 4000$ counts). Scanning electron microscopy was used to study surface morphology of alloy deposits coated over polished copper surface.

\section{Results and Discussion}

\subsection{Cathodic Polarization Characteristics}

Fig. 1 shows the cathodic polarization curves for Zn-Co alloy deposition on copper cathode (curve 3). Figure also shows the polarization characteristics for the deposition of individual metals as well (curves 1 and 2). The deposition potential for cobalt was around $-1.0 \mathrm{~V}$, whereas for Zinc, it is $-1.20 \mathrm{~V}$ and the deposition potential for $\mathrm{Zn}$-Co alloy (curve 3) was at $1.40 \mathrm{~V}$. The position of $\mathrm{Zn}$-Co alloy deposition potential curve is shown to be more negative to less noble zinc. This clearly indicates why zinc deposits preferentially over cobalt i.e., anomalous co-deposition. The bath solution contained same concentration of cobalt and zinc as those in the individual baths.

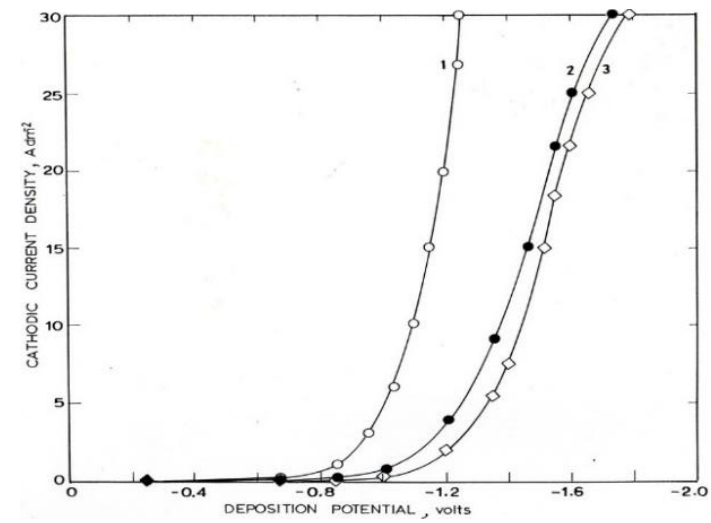

Fig. 1 Cathodic polarization curves for the deposition of zinc, cobalt and $\mathrm{Zn}$-Co alloy from an acid sulphate bath. All solution contained TEA $40 \mathrm{~mL} / \mathrm{L}, \mathrm{H}_{3} \mathrm{BO}_{3} 25 \mathrm{~g} / \mathrm{L}$, stirred conditions. Curve 1: Deposition of cobalt; Curve 2: Deposition of zinc; Curve 3: Deposition of zinc-cobalt alloy.

\subsection{Effect of Metal Ion Ratio in the Bath}

To study the effect of metal ion ratio in the bath on alloy composition, the bath contained zinc to cobalt ratio varied from 86:14 to 98:2. Fig. 2 shows the variation of alloy composition with bath composition obtained at three different current densities $\left(2.5,10\right.$ and $\left.30 \mathrm{Adm}^{-2}\right)$. A bath solution containing $11 \%$ Co produced an alloy deposit with $0.6 \%$ Co indicating preferential deposition of zinc (anomalous process). 




Fig. 2 Dependence of the \%Co in alloy with the \%Co in the bath. Bath composition: Total metal content $0.2 \mathrm{M},\left[\mathrm{Zn}^{2+}\right] 0.172-0.196 \mathrm{M},\left[\mathrm{Co}^{2+}\right] 0.022 \mathrm{M}$, TEA $40 \mathrm{~mL} / \mathrm{L}$, thiaminehydrochloride $0.4 \mathrm{~g} / \mathrm{L}, \mathrm{Na}_{2} \mathrm{SO}_{4} 30 \mathrm{~g} / \mathrm{L}, \mathrm{H}_{3} \mathrm{BO}_{3} 25 \mathrm{~g} / \mathrm{L}$, pH 5.0, temperature 35

${ }^{\circ} \mathrm{C}$, current density 2.5-30 $\mathrm{Adm}^{-2}$, thickness $\sim 6 \mu \mathrm{m}$, stirred condition. Curve 1: 30 Adm $^{-2}$; Curve 2: $10 \mathrm{Adm}^{-2}$; Curve 3: $2.5 \mathrm{Adm}^{-2}$

\subsection{Effect of $p H$}

Increase in the bath $\mathrm{pH}$ resulted in increase in the percentage of cobalt in the alloy deposit (Fig. 3).



Fig. 3 Variation of \%Co in the alloy with the $\mathrm{pH}$ of the plating bath. bath composition: Total metal content $0.2 \mathrm{M},\left[\mathrm{Zn}^{2+}\right] 0.172-0.196 \mathrm{M},\left[\mathrm{Co}^{2+}\right] 0.004-0.028 \mathrm{M}$, TEA 40 $\mathrm{mL} / \mathrm{L}$, thiaminehydrochloride $0.4 \mathrm{~g} / \mathrm{L}, \mathrm{Na}_{2} \mathrm{SO}_{4} 30 \mathrm{~g} / \mathrm{L}, \mathrm{H}_{3} \mathrm{BO}_{3} 25 \mathrm{~g} / \mathrm{L}$, temperature 35 ${ }^{\circ} \mathrm{C}$, current density $10 \mathrm{Adm}^{-2}$, pH 4-6, thickness $\sim 6 \mu \mathrm{m}$, stirred condition. Curve 1 : 86/14 Zn/Co, Curve 2: 89/11 Zn/Co, Curve 3: 92/8 Zn/Co.

\subsection{Effect of Current Density}

Increase in current density increases \%Co in the alloy deposit (Fig. 4). This is attributed to the preferential deposition of zinc in the cathode diffusion layer due to its rapid depletion than cobalt, i.e., diffusion controlled.

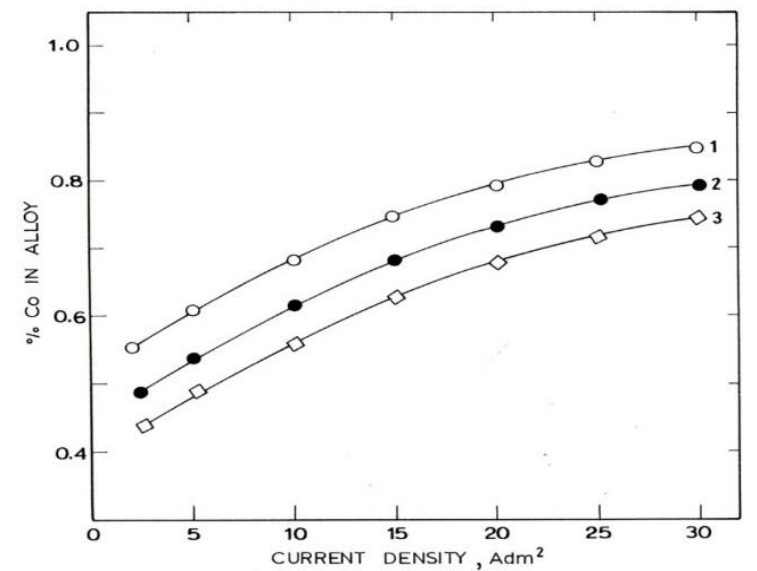

Fig. 4 Variation of $\%$ of Co in the alloy with the current density. Bath composition: Total metal content $0.2 \mathrm{M}$, $\left[\mathrm{Zn}^{2+}\right] 0.172-0.196 \mathrm{M},\left[\mathrm{Co}^{2+}\right] 0.004-0.028 \mathrm{M}$, TEA 40 $\mathrm{mL} / \mathrm{L}$, thiaminehydrochloride $0.4 \mathrm{~g} / \mathrm{L}, \mathrm{Na}_{2} \mathrm{SO}_{4} 30 \mathrm{~g} / \mathrm{L}, \mathrm{H}_{3} \mathrm{BO}_{3} 25 \mathrm{~g} / \mathrm{L}$, temperature 35 ${ }^{\circ} \mathrm{C}$, current density $2.5-30 \mathrm{Adm}^{-2}$, $\mathrm{pH} 5.0$, thickness $\sim 6 \mu \mathrm{m}$, stirred condition. Curve 1 : 86/14 Zn/Co, Curve 2: 89/11 Zn/Co, Curve 3: 92/8 Zn/Co. https://doi.org/10.30799/jacs.228.21070101

\subsection{Effect of Temperature}

To study the effect of temperature on alloy composition, experiments were conducted at different temperatures $\left(25-30{ }^{\circ} \mathrm{C}\right)$. Fig. 5 illustrates the dependence of alloy composition on temperature of the plating bath. An increase in temperature increased the \%Co in the alloy deposit.

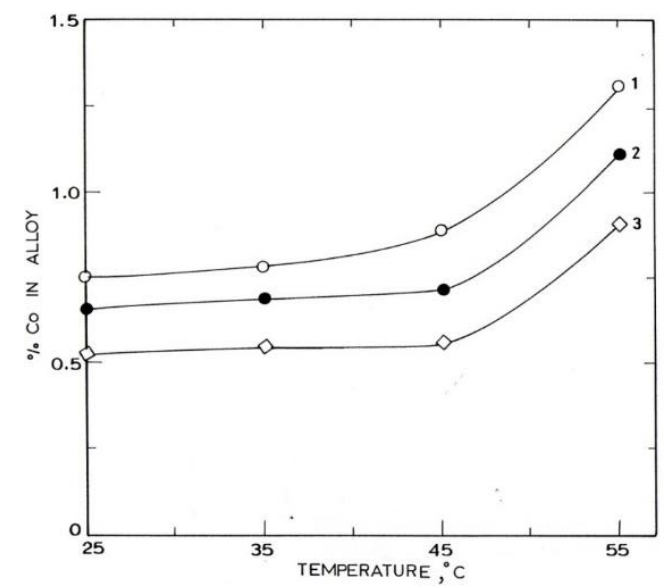

Fig. 5 Variation of the \%Co in alloy with temperature of the operating bath. Bath composition: Total metal content $0.2 \mathrm{M},\left[\mathrm{Zn}^{2+}\right] 0.178 \mathrm{M},\left[\mathrm{Co}^{2+}\right] 0.022 \mathrm{M}$, TEA $40 \mathrm{~mL} / \mathrm{L}$ thiaminehydrochloride $0.4 \mathrm{~g} / \mathrm{L}$, current density $2.5-3.0 \mathrm{Adm}^{-2}, \mathrm{pH} \mathrm{5.0}$, thickness $\sim 6$ $\mu \mathrm{m}$, stirred condition. Curve 1: $30 \mathrm{Adm}^{-2}$; Curve 2: $10 \mathrm{Adm}^{-2}$; Curve 3: $2.5 \mathrm{Adm}^{-2}$.

\subsection{Effect of Triethanolamine (TEA) and Thiamine Hydrochloride}

Variation of Zn-Co alloy composition with concentrations of TEA and thiaminehydrochloride is shown in Fig. 6. Increase in TEA concentration, increases \% Co in the alloy, whereas increase in the concentration of thiaminehydrochloride decreased the percentage of cobalt in the alloy deposit.

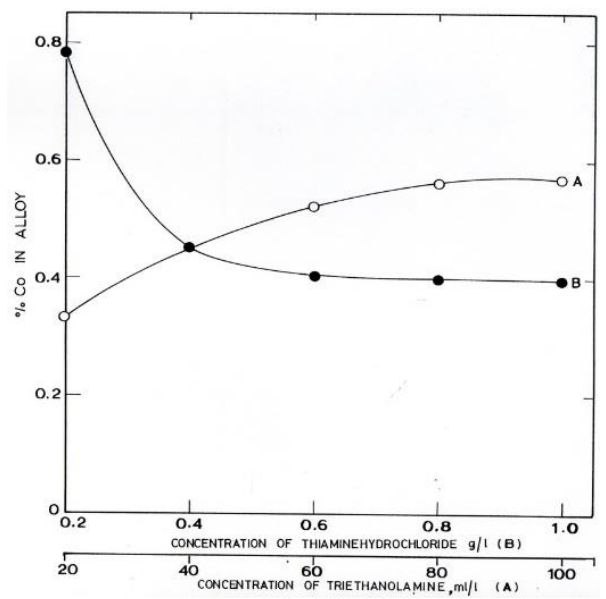

Fig. 6 Effect of TEA and Thiaminehydrochloride concentrations on the composition of $\mathrm{Zn}$-Co alloy. Total metal content $0.2 \mathrm{M},\left[\mathrm{Zn}^{2+}\right] 0.178 \mathrm{M},\left[\mathrm{Co}^{2+}\right] 0.022 \mathrm{M}$, TEA 40 $\mathrm{mL} / \mathrm{L}$, thiaminehydrochloride $0.4 \mathrm{~g} / \mathrm{L}$, current density $2.5-3.0 \mathrm{Adm}^{-2}, \mathrm{pH} 5.0$ thickness $\sim 6 \mu \mathrm{m}$, stirred condition.

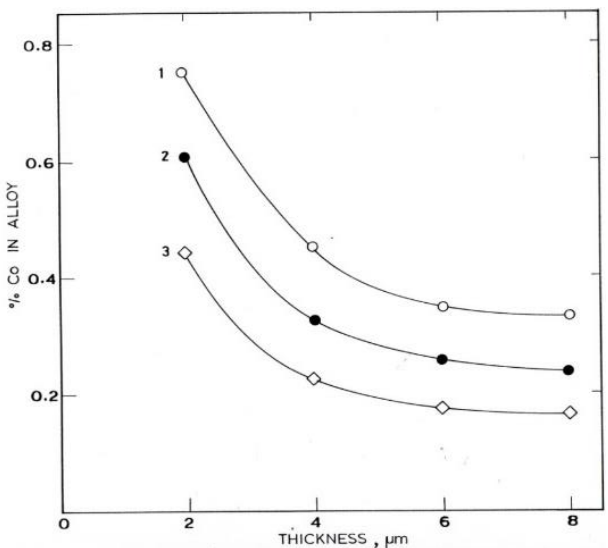

Fig. 7 Dependence of composition of alloy with thickness of the alloy deposit. Bath Fig. 7 Dependence of composition of alloy with thickness of the alloy deposit. Bath
composition: Total metal content $0.2 \mathrm{M},\left[\mathrm{Zn}^{2+}\right] 0.172-0.196 \mathrm{M},\left[\mathrm{Co}^{2+}\right] 0.004-0.028$ $\mathrm{M}$, TEA $40 \mathrm{~mL} / \mathrm{L}$, thiaminehydrochloride $0.4 \mathrm{~g} / \mathrm{L}, \mathrm{Na}_{2} \mathrm{SO}_{4} 30 \mathrm{~g} / \mathrm{L}, \mathrm{H}_{3} \mathrm{BO}_{3} 25 \mathrm{~g} / \mathrm{L}$, temperature $35{ }^{\circ} \mathrm{C}, \mathrm{pH} 5.0$, current density $10 \mathrm{Adm}^{-2}$, thickness $2-8 \mu \mathrm{m}$, stirred condition. Curve 1: 86/14 Zn/Co, Curve 2: 89/11 Zn/Co, Curve 3: 92/8 Zn/Co. 


\subsection{Effect of Thickness}

Increase in the thickness of alloy deposit decreased the percentage of cobalt in the alloy deposit (Fig. 7). This might be due to the depletion in concentration of cobalt metal in the cathode diffusion layer.

\subsection{Effect of Stirring}

The percentage of cobalt in the alloy deposit was found to be more under stirred conditions compared to unstirred conditions (Table 1).

Table 1 Composition of Zn-Co alloy with and without stirring of the bath solution

\begin{tabular}{llll}
\hline & \% Co in alloy & & \\
\cline { 2 - 4 } & $2.5 \mathrm{Adm}^{-2}$ & $10 \mathrm{Adm}^{-2}$ & $30 \mathrm{Adm}^{-2}$ \\
\hline \multirow{2}{*}{ With stirring } & 0.55 & 0.70 & 0.78 \\
& $(86.29)$ & $(52.54)$ & $(42.20)$ \\
Without stirring & 0.62 & 0.79 & 0.85 \\
& $(78.64)$ & $(45.62)$ & $(27.44)$
\end{tabular}

The cathodic current efficiency is given in parenthesis. Bath composition: Total metal content $0.2 \mathrm{M}\left[\mathrm{Zn}^{2+}\right] 0.178 \mathrm{~m},\left[\mathrm{Co}^{2+}\right] 0.022 \mathrm{M}, \mathrm{TEA} 40 \mathrm{~mL} / \mathrm{L}$, Thiamine hydrochloride 0.4 $\mathrm{g} / \mathrm{L}, \mathrm{Na}_{2} \mathrm{SO}_{4} 30 \mathrm{~g} / \mathrm{L}, \mathrm{H}_{3} \mathrm{BO}_{3} 25 \mathrm{~g} / \mathrm{L}$, temperature $35^{\circ} \mathrm{C}, \mathrm{Cd} 2.5-30 \mathrm{Adm}^{-2}, \mathrm{pH}$ 5.0, thickness $\sim 6 \mu \mathrm{m}$.

\subsection{Cathodic Current Efficiency}

Cathodic current efficiencies (CCE) were calculated for each experiment at any given temperature, current density and stirring of the bath solution. Dependency of CCE on current density is shown in Fig. 8. Increase in current density decreases CCE of alloy plating. This is probably due to more hydrogen discharge at higher current densities. Increase in temperature of plating bath decreases CCE (Table 2). It was also noticed that CCE was higher under stirred conditions compared to unstirred conditions (Table 1).

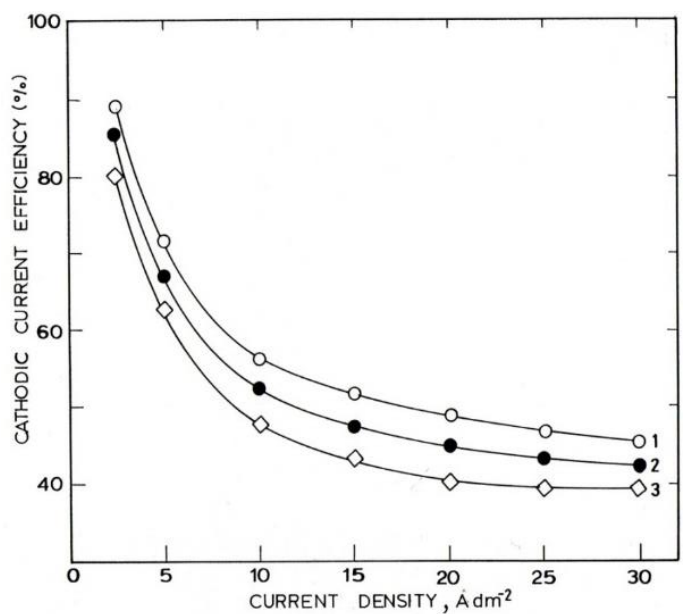

Fig. 8 Dependence of cathodic current efficiency with current density. Bath composition. Total metal content $0.2 \mathrm{M}$, $\left[\mathrm{Zn}^{2+}\right] 0.172-0.196 \mathrm{M}$, [Co $\left.{ }^{2+}\right] 0.004-0.028$ $\mathrm{M}$, TEA $40 \mathrm{~mL} / \mathrm{L}$, thiaminehydrochloride $0.4 \mathrm{~g} / \mathrm{L}, \mathrm{Na}_{2} \mathrm{SO}_{4} 30 \mathrm{~g} / \mathrm{L}, \mathrm{H}_{3} \mathrm{BO}_{3} 25 \mathrm{~g} / \mathrm{L}$, temperature $35{ }^{\circ} \mathrm{C}$, current density $2.5-30 \mathrm{Adm}^{-2}$, pH 5.0, thickness $\sim 6 \mu \mathrm{m}$, stirred condition. Curve 1: 86/14 Zn/Co, Curve 2: 89/11 Zn/Co, Curve 3: 92/8 Zn/Co

Table 2 Effect of temperature on cathodic current efficiency of Zn-Co alloy deposition

\begin{tabular}{llll}
\hline \multirow{2}{*}{ Temperature $\left({ }^{\circ} \mathrm{C}\right)$} & \multicolumn{4}{l}{ Cathodic current efficiency $(\%)$} \\
\cline { 2 - 4 } & $2.5 \mathrm{Adm}^{-2}$ & $10 \mathrm{Adm}^{-2}$ & $30 \mathrm{Adm}^{-2}$ \\
\hline 25 & 89.30 & 84.15 & 67.21 \\
35 & 86.29 & 80.35 & 64.18 \\
45 & 85.17 & 76.63 & 55.67 \\
55 & 85.17 & 67.81 & 42.10 \\
\hline
\end{tabular}

\subsection{Properties}

The adhesion of alloy deposits to the base metal was tested by a bending test. Alloy deposits did not show any visual cracks even after $180^{\circ}$ bending. This shows good adhesion of Zn-Co alloy deposits to the substrate. Ferroxyl test was conducted for Zn-Co alloy coated on steel. Alloy deposits with sufficient thickness ( $>6 \mu \mathrm{m}$ ) were free from pores. Microchardness of alloy deposits was determined on Vickers scale (load $50 \mathrm{~g}$ ). Hardness of the alloy increases with an increase in the amount of cobalt in the deposit (Table 3). The static potentials of zinc and Zn-Co alloy coated on steel panels were measured with respect to SCE in $3.5 \% \mathrm{NaCl}$ solution. Static potentials of alloy were less negative to zinc and more negative to mild steel (Table 3). Zn-Co alloy deposits were found to protect steel much more effectively than pure zinc coatings.

https://doi.org/10.30799/jacs.228.21070101
Table 3 Effect of cobalt content on microhardness and static potentials of Zn-Co alloy

\begin{tabular}{lll}
\hline \% Co in alloy & $\begin{array}{l}\text { Microhardness in VHN (load } \\
-50 \mathrm{~g})\end{array}$ & $\begin{array}{l}\text { Static potential in mV versus SCE } \\
\text { measured in } 3.5 \% \mathrm{NaCl} \text { solution }\end{array}$ \\
\hline Zinc & 90 & -1036 \\
Zn-0.4\% Co & 185 & -1001 \\
Zn-0.6\% Co & 206 & -991 \\
Zn-0.8\% Co & 220 & -984 \\
Zn-1.0\% Co & 229 & -976 \\
Zn-1.2\% Co & 234 & -955 \\
Mild Steel & - & -582 \\
\hline
\end{tabular}

\subsection{Structure and Morphology}

The phase structure of electrodeposited Zn-Co alloy from an acid sulphate bath containing TEA and thiaminehydrochloride was determined by X-ray analysis. It is found that Zn-Co alloy forms zinc structure of solid solution type $\eta$-phase (Fig. 9). The surface morphology of Zn-Co alloy deposits was examined by scanning electron microscopy. Fig. 10 shows the changes in surface morphology of deposits with \%Co in the alloy deposits.

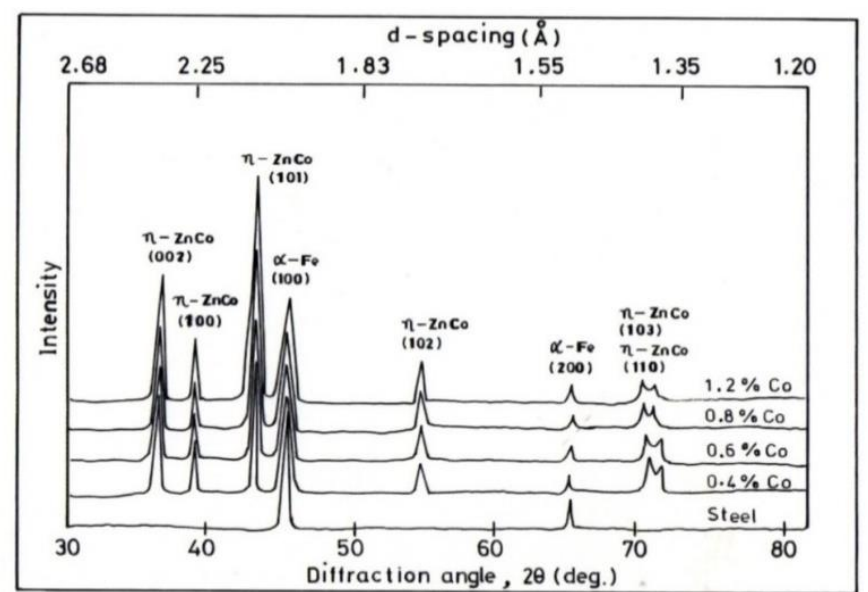

Fig. $9 \mathrm{X}$-ray powder diffraction patterns for electrodeposited zinc and $\mathrm{Zn}$-Co alloy deposits obtained from an acid sulphate bath

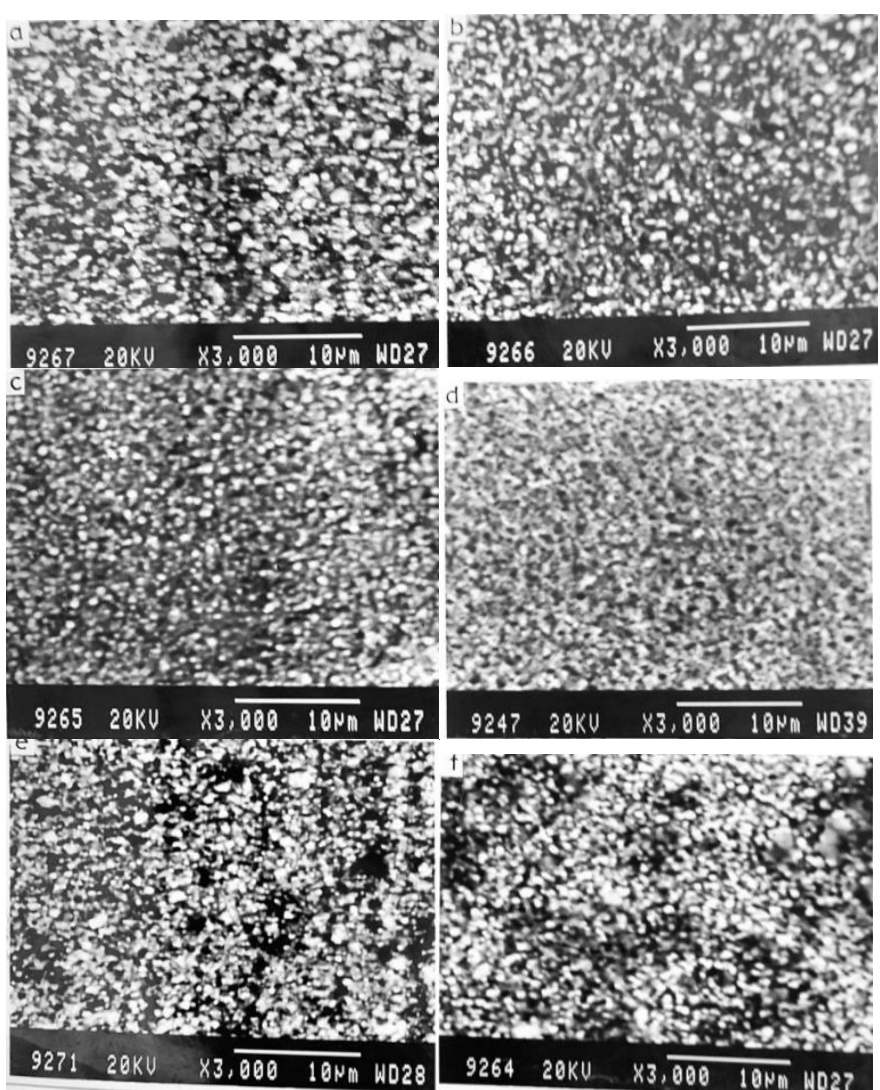

Fig. 10 Scanning electron micrographs of zinc and zinc-cobalt alloy deposits containing different \%Co from an acid sulphate bath containing TEA and thiaminehydrochloride $(\times 3000-4000)$. a) $0 \%$ Co, (b) $0.4 \%$ Co, (c) $0.9 \%$ Co, (d) 0.8 $\%$ Co, (e) $1.0 \%$ Co and (f) $1.2 \%$ Co 
Table 4 gives the optimum bath composition and operating conditions for electrodeposition of $\mathrm{Zn}$-Co alloy containing $0.4-1.2 \%$ Co.

Table 4 Optimum bath composition and operating conditions

\begin{tabular}{ll}
\hline Bath Component & Optimum bath composition and operating conditions \\
\hline Total metal content & $0.2 \mathrm{M}$ \\
$\mathrm{ZnSO}_{4} .7 \mathrm{H}_{2} \mathrm{O}$ & $0.178 \mathrm{M}$ \\
$\mathrm{CoSO}_{4} \cdot 6 \mathrm{H}_{2} \mathrm{O}$ & $0.022 \mathrm{M}$ \\
Triethanolamine & $40 \mathrm{~mL} / \mathrm{L}$ \\
$\mathrm{Thiaminehydrochloride}$ & $0.4 \mathrm{~g} / \mathrm{L}$ \\
$\mathrm{Na}_{2} \mathrm{SO}_{4}$ & $30 \mathrm{~g} / \mathrm{L}$ \\
$\mathrm{H}_{3} \mathrm{BO}_{3}$ & $25 \mathrm{~g} / \mathrm{L}$ \\
$\mathrm{pH}$ & 5.0 \\
Temperature & $35^{\circ} \mathrm{C}$ \\
Current density & $10 \mathrm{Adm}$ \\
Stirring & Normal \\
\hline
\end{tabular}

\section{Conclusion}

Eletrodeposition of Zn-Co alloy from an acid sulphate bath containing TEA and thiaminehydrochloride follows potential curve for alloy was formed to lie in the right of Zinc deposition potential curve. Increase in $\mathrm{pH}$, current density, concentration of TEA and stirring of bath solution increased \%Co in the alloy. The CCE was found to decrease with current density temperature and increase with stirring of the bath solution. The phase structure of $\mathrm{Zn}$-Co alloy is a solid solution ( $\eta$-phase). The surface morphology of the alloy changed with the amount of cobalt in the deposit.

\section{References}

[1] Z.M. Tu, J.S. Zhang, L. Wennliang, Z.L. Yang, A. Maozhong, The electrodeposition of Zn-Co alloy from a zincate bath, Trans. IMF - Int. J. Surf. Eng. Coat. 73(2) (1995) 48-49.
[2] V. Narasimhamurthy, B.S. Sheshadri, Electrodeposition of zinc-cobalt alloy from ankaline sulfate bath containing triethanolamine and gelatin, Met. Fin. 96(4) (1998) 24-27.

[3] V. Narasimhamurthy, B.S. Sheshadri, Physico-chemical properties of Zn-Co alloy deposits from an alkaline sulphate bath containing triethanolamine and gelatin,Trans. IMF 77 (1999) 29-30.

[4] K. Arunprasad, P. Giridhar, V. Ravindran, V.S. Muralidharan, Zinc-cobalt alloy electrodeposition and characterisation, J. Solid State Electrochem. 6(1) (2001) 63-68.

[5] J.B. Bajata, V.B. Mišković-Stankovića, M.D. Maksimovića, D.M. Dražić Electrochemical deposition and characterization of Zn-Co alloys and corrosion protection by electrodeposited epoxy coating on Zn-Co alloy, Electrochim. Acta 47(25) (2002) 4101-4112.

[6] G. Trejo, R. Ortega, Y. Meas, E. Chainet, P. Ozil, Effect of benzylideneacetone on the electrodeposition mechanism of Zn-Co alloy, J. App. Electrochem. 33 (2003) 373-379.

[7] Jing-Yin Fei, G.D. Wilcox, Electrodeposition of Zn-Co alloys with pulse containing reverse current, Electrochim. Acta 50(13) (2005) 2693-2698.

[8] A. Chitharanjan Hegde, V. Thangaraj, Electrodeposition and characterization Zn-Co alloy, Rus. J. Elect. Chem. 45 (2009) 756-761.

[9] M.S. Chandrasekar, S. Srinivasan, P. Malathy, Properties of zinc alloy electrodeposits produced from acid and alkaline electrolytes, J. Solid State Electrochem. 13 (2009) 781-789.

[10] S. Yogesha, A. Chitharanjan Hegde, Corrosion resistant Zn-Co alloy coatings deposited using saw-tooth current pulse, Bull. Mater. Sci. 34(7) (2011) 16991706.

[11] I.H. Karahan, H.A. Cetinkara, Study of effect of boric acid on Zn-Co alloy electrodeposition from acid baths and on composition, morphology and structure of deposit, Trans. IMF 89(2) (2011) 99-103.

[12] Hiroaki Nakano, Shitoku Shibata, Shingo Arakawa, Satoshi Oue, Shigeo Kobayashi, Electrodeposition behaviour of Zn-Co alloys from an alkaline zincate solution containing triethanolamine, ISIJ Int. 53(10) (2013) 18581863.

[13] Julyana Ribeiro Garcia, Dalva Cristina Baptista do Lago, Lilian Ferreira de Senna, Electrodeposition of cobalt rich $\mathrm{Zn}$-Co alloy coatings from citrate bath, Mat. Res. 17(4) (2014) 947-957.

[14] F. Azizi, A. Kahoul, Electrodeposition and corrosion behaviour of Zn-Co coating produced from a sulphate bath, Int. J. Surf. Eng. Coat. 94(1) (2016) 43-48. 